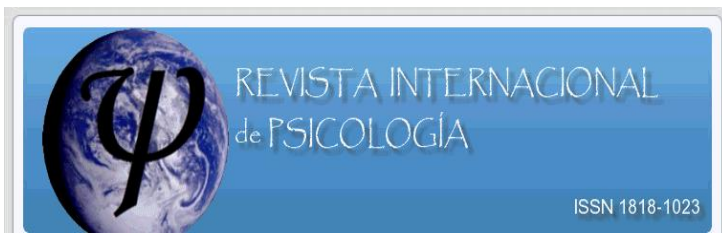

Cambios y permanencias en la representación social del VIH en un grupo de mujeres portadoras

Changes and stagnation in a social representation of an HIV seropositive women

\author{
Maestra Ana Celia Chapa Romero
}

Dra. Fátima Flores Palacios

Universidad Nacional Autónoma de México

\title{
Nota sobre las autoras
}

Ana Celia Chapa Romero. Candidata a Doctora en Psicología y Salud por la Universidad Nacional Autónoma de México (UNAM). Coordinación de investigación y producción científica de la Universidad de Londres.

Fátima Flores Palacios. Doctora en Psicología por la Universidad Autónoma de Madrid. Centro Peninsular en Humanidades y Ciencias Sociales de la UNAM.

Remita cualquier duda sobre este artículo al siguiente domicilio: Tabasco 329, Col. Roma, Del. Cuauhtémoc, 06700 México D.F. anachaparo2000@yahoo.com.mx 


\section{Resumen}

A 30 años de la aparición del primer caso de Síndrome de Inmunodeficiencia Humana en México, el curso de este padecimiento ha experimentado cambios significativos, entre ellos su actual carácter de enfermedad crónica y un aumento de infecciones en grupos no considerados clave, particularmente en población femenina. Desde la teoría de las representaciones sociales esta enfermedad ha sido un objeto de estudio privilegiado, aunque la experiencia de vivir con la enfermedad y la condición de género en la construcción de dichas representaciones han sido abordadas en menor medida. El objetivo de esta investigación fue conocer la representación social que un grupo de mujeres seropositivas ha elaborado sobre su condición de salud, ubicando los cambios y permanencias a partir de su diagnóstico y condición de género. Se llevaron a cabo 12 entrevistas en profundidad con usuarias de dos centros de atención primaria y se realizó análisis de contenido por medio del software N Vivo. El análisis de las entrevistas arrojó 12 categorías que fueron agrupadas en tres meta categorías que develaron 2 tipos de contenidos representacionales en la muestra estudiada: hegemónicos (muerte, sexualidad ilícita) y emancipados (cronicidad). Los hallazgos pusieron de manifiesto por un lado, la vigencia del sistema de normas y valores sobre género y sexualidad arraigados en el pensamiento social pese a los avances científicos que se han dado en el campo de la salud y; por otro, una negociación de significados a partir de la experiencia vivida. Se recomienda para futuras investigaciones llevar a cabo diversas comparaciones entre grupos de mujeres con VIH con el objetivo de poder establecer diferencias más precisas en cuanto a posicionamiento social y contenidos representacionales, que permitan desarrollar estrategias eficaces y pertinentes tanto en prevención primaria como positiva.

Palabras clave: Representaciones sociales, VIH, Género. 


\begin{abstract}
At 30 years of the onset of the first case of Human Immunodeficiency Syndrome in Mexico, the disease has changed during these decades, including its current status as a chronic illness and the spread of it in non-risk groups such as women. From the theory of social representations this disease has been a privileged object of study, but the experience of living with the disease and the condition of gender in the construction of such representations have been addressed to a lesser extent. The aim of this research was to determine the social representation women living with HIV has developed on their health conditions, placing change and permanence, from a diagnosis. There were carried out 12 in-depth interviews with participants from two primary care centers, and it was conduced a categorical content analysis using N Vivo software. The results were classified in 12 categories which were grouped into three meta categories 2 types of representational content in the sample: hegemonic (death, illicit sexuality) and emancipated (chronicity).The findings revealed the prevalence of traditional norms and values about gender and sexuality rooted in social thinking despite the scientific advances in the field of health. Furthermore, it was found a negotiation of meaning based on experience. Further research is recommended to carry out comparisons between groups of women with HIV in order to be able to establish more precise differences in social position and representational content, in order to develop effective and relevant in both primary prevention and positive strategies
\end{abstract}

Keywords: Social representations, HIV, Gender. 


\section{Introducción}

De acuerdo a datos proporcionados por el Centro Nacional para la Prevención y el Control del VIH/SIDA (CENSIDA)hasta el primer semestre del 2013 se tenían diagnosticados y notificados en México 3,425 casos de síndrome de inmunodeficiencia adquirida (SIDA) y 3,090 de virus de inmunodeficiencia humana (VIH). Al cierre de dicho año, se estimó una prevalencia de VIH de $0.3 \%$ en población mexicana, ${ }^{1}$ observándose una prevalencia por encima del 5\%en subgrupos o poblaciones clave como hombres que tienen sexo con hombres (HSH), trabajadores sexuales, usuarios de drogas inyectadas y personas privadas de la libertad (CENSIDA, 2013).

Cabe resaltar que las muertes asociadas al SIDA han disminuido significativamente en los últimos años gracias al desarrollo del Tratamiento Antirretroviral Altamente Supresivo (TAAR), y a la movilización de miembros de organizaciones no gubernamentales y gubernamentales para lograr la cobertura universal y gratuita de este. Por lo tanto, esta enfermedad ha pasado de mortal e incurable acrónica y tratable.

Respecto a las nuevas infecciones, en el Informe Nacional de Avances en la Lucha contra el Sida, emitido por la Secretaria de Salud y CENSIDA en el 2013, se reporta un descenso constante en estas desde 1996, permaneciendo estable desde entonces a 100.000 [73.000 -135.000] por año en los subgrupos o poblaciones clave antes mencionadas.

Un fenómeno que ha llamado la atención es que a la par de la disminución de infecciones en grupos clave, se ha venido dando un incremento en el número de infecciones en mujeres de todas las regiones del mundo. En el caso de las mujeres mexicanas la epidemia

\footnotetext{
1 Tasa por 100,000 habitantes.
} 
no ha alcanzado aún la prevalencia ni la proporción hombre/mujer que existe en otras partes del mundo como África Subsahariana, no obstante se ha observado un incremento en esta proporción durante las últimas décadas. Así, mientras en 1985 por cada 11 casos de Sida en varones había una mujer, para mediados de la década de los noventa esta proporción se fue cerrando hasta llegar a 5 hombres por una mujer. Actualmente la razón estimada es de cuatro a una, encontrándose variaciones por entidad federativa y tipo de localidad (CENSIDA, 2013).

Investigaciones llevadas a cabo en México (Allen y Torres, 2008;Théodore, Gutiérrez, Torres y Luna, 2004;Torres, Zarco y Allen-Leigh,2010;Villaseñor, Caballero, Hidalgo y Santos, 2003) y Brasil (Abreu, Santos, Freitas y Nóbrega,2012; Giacomozzi y Vizeu, 2004) han puesto de relieve que situaciones como el machismo, la violencia, la dependencia económica y/o emocional y creencias sobre los roles de género, dificultan el control en el terreno de la sexualidad, posicionando a las mujeres en un riesgo mayor de adquirir alguna infección de transmisión sexual incluido el VIH. Se debe destacar también que, el hecho de que la epidemia se haya concentrado en determinados subgrupos que históricamente han sido estigmatizados como homosexuales, drogodependientes, trabajadores y trabajadoras sexuales, ha reforzado mecanismos de control y normatización social ejercidos a través de discursos como el de "grupos de riesgo" (Horton y Aggleton, 1990Joffe, 1995), situación que por un lado ha agudizado la discriminación hacia estos grupos y por otro, ha generado percepciones de invulnerabilidad y distanciamiento frente al virus en población general.

Una de las teorías que se ha ocupado de estudiar el carácter social de los conceptos y explicaciones que las personas hacen del VIH/SIDA y la función social que tienen discursos sobre el riesgo y a quienes se considera en riesgo, es la teoría de las representaciones sociales (TRS). Las representaciones sociales (r.s.) son una forma de conocimiento socialmente 
compartido, que orientan a la gente en una realidad común. En este orden de ideas, esta teoría ha permitido construir un puente para la explicación de los procesos individuales e interindividuales, empleando las condiciones sociales como elementos explicativos (Moscovici, 1979).La noción de r.s. involucra lo psicológico o cognitivo y lo social, fundamentando que el conocimiento se constituye a partir de las experiencias personales y de las informaciones y modelos de pensamiento que recibimos a través de la sociedad.

Dicho de otra manera, las r.s. son una forma de conocimiento socialmente elaborado y compartido, orientado hacia la práctica y la construcción de una realidad común a un conjunto social. En este sentido, lo social se puede interpretar de varias maneras: "por medio del contexto concreto en que se sitúan las personas, por la comunicación que se establece entre ellas, y por los marcos de aprehensión de valores, culturas, códigos e ideologías relacionadas con el contexto social en que se encuentran inmersas" (Jodelet, 1986, p. 213).

Moscovici (1988) identifica tres formas en que las representaciones pueden ser sociales, en función de las relaciones entre los miembros del grupo:

1. Las representaciones pueden ser compartidas por todos los miembros de un grupo altamente estructurado - un partido, una nación- sin que hayan sido producidas por el grupo. Estas representaciones hegemónicas prevalecen implícitamente en toda práctica simbólica o afectiva. Parecen ser uniformes y coercitivas.

2. Otras representaciones son producto de la circulación de conocimientos e ideas pertenecientes a subgrupos que están más o menos en contacto. Cada subgrupo crea su propia versión y la comparte con los otros. Éstas son representaciones emancipadas, con cierto grado de autonomía y resultan de compartir e intercambiar un conjunto de 
interpretaciones y símbolos. Son sociales en virtud de la división de funciones y de la información que se reúne y combina a través de ellas.

3. Por último hay representaciones generadas en el curso de conflictos sociales, controversias sociales, y la sociedad como un todo no las comparte, estás son representaciones polémicas. Ellas están determinadas por relaciones antagónicas entre sus miembros e intentan ser mutuamente excluyentes.

Wagner y Hayes (2011) sugieren que los cambios en las condiciones de vida y de comportamiento necesariamente conducen a la transformación de las representaciones hegemónicas en los grupos. Añaden que frente a los cambios o las nuevas condiciones, se dan procesos de adaptación colectivos e individuales que pueden causar representaciones incompatibles, dentro de y entre los grupos, es decir representaciones emancipadas o polémicas.

Uno de los campos que permite acceder al estudio de las transformaciones de las r.s., es el de la enfermedad, pues esta impacta varias dimensiones (psicológica, social, económica) trayendo consigo importantes cambios en las condiciones de vida de quienes la padecen (Jodelet, 2004; Konstantinidis y Cabello, 2008; Herzlich y Pierret, 1988).

Diversas investigaciones conformadas por muestras de personas seronegativas principalmente jóvenes- han encontrado dentro de las asociaciones más comunes y frecuentes al VIH/SIDA palabras como: enfermedad, muerte, miedo, homosexualidad, contaminación, contagio, infidelidad, promiscuidad, prostitución, drogas, irresponsabilidad, sexo casual. Estos elementos han sido consistentes en todos los grupos estudiados independientemente de la región y contexto (Abreu et. al.,2012; Chong, Torres y López 2007; Flores y Alba, 2006; Flores y Leyva, 2003; Fonseca, 2009; Giacomozzi y Vizeu, 2004;Goodwin, Kwiatkowska, 
Realo, Kozlova, Nguyen y Nizharadze, 2004; Joffe, 1995; Madeira 1998; Morin, 1994; Petracci, 1997) así como del nivel de información sobre los aspectos biomédicos de esta afección (Flores y Alba, 2006; Flores y Leyva, 2003; Goodwinet al., 2004; Jofré, Marin y Yuli, 2005; Oliveira y Lessa da Costa, 2007). La homogeneidad en los resultados de dichas investigaciones ha llevado a definir a la enfermedad, la muerte y la sexualidad, como los contenidos que delinean el campo representacional del VIH/SIDA, o dicho desde una perspectiva más estructural, como el núcleo central de esta (Abric, 1993). A la par de estos hallazgos, también se ha reportado un componente actitudinal negativo en torno a la infección y a las personas afectadas que muestra una moralización en las prácticas sexuales (Abreu et al. 2012; Chong et al. 2007; Fonseca, 2009; Joffe, 1995; Morin, 1994). Otro aspecto a resaltar es que el nivel de información o conocimiento de corte biológico sobre el virus se asume como factor protector en la mayoría de grupos, pese a que en sus prácticas sexuales reportan un uso "selectivo" del condón (Chong et al.2007; Flores y Leyva, 2003; Fonseca, 2009; Giacomozzi y Vizeu, 2004; Madeira, 1998; Morin, 1994), lo que explicaría en gran medida la propagación del virus en población no considerada clave.

En estudios conformados por muestras de personas seropositivas, se han encontrado contenidos en el campo representacional similares a los de personas seronegativas, principalmente los referentes a la muerte y la sexualidad(Fonseca, 2009;Grimberg, 2009; Pereira y Arruda, 2005; Pierret, 2000).No obstante, se reportan diferencias importantes en cuanto a la cantidad y calidad de las asociaciones relacionadas al conocimiento científico sobre la infección (el conocimiento es mayor y basado en evidencia científica) y nuevos significados que permiten cuestionar nociones como la de irresponsabilidad individual en la adquisición del virus. Asimismo, se pueden observar diferencias en torno al estigma en sus dimensiones emocional (tristeza, soledad, desesperación)y relacional(agente de contagio, 
sexo peligroso), en donde el género parece jugar un papel central (Fonseca, 2009; Grimberg, 2009; Pereira y Arruda, 2005).En un estudio realizado por Grimberg (2009), en donde a través de entrevistas cualitativas profundiza más en los significados otorgados al VIH en hombres y mujeres, se encontró que en las primeras el cuerpo era significado como "agente de contagio" (sexual o vertical) o como "vacío de sentido"(en aquellas que habían renunciado a la maternidad); mientras que para los varones era experimentado como un cuerpo "frágil", “débil" y "peligroso". Por su parte, Pereira y Arruda (2005) encontraron que si bien los hombres manifestaron diversas perdidas a raíz del diagnóstico (empleo, amigos, planes), también rescataron cambios internos positivos a diferencia de las mujeres, quienes relatan un mayor número de pérdidas (principalmente en las esferas de la sexualidad y la salud) y cambios internos predominantemente negativos. Otro dato interesante fue el referente al tiempo de diagnóstico, observándose que aquellas y aquellos con mayor tiempo de diagnóstico y adherentes al tratamiento antirretroviral, lograron centrarse más en sus habilidades y recursos de afrontamiento e hicieron valoraciones más positivas en torno a la infección (Fonseca, 2009; Pereira y Arruda, 2005; Pierret, 2000).

La literatura sobre representaciones sociales y VIH/SIDA, permite ver que este tema ha sido un objeto de estudio privilegiado para la teoría. No obstante, se debe mencionar que la mayor parte de la producción sobre el tema ha estado centrada en muestras de personas seronegativas, pertenecientes a contextos urbanos y particularmente jóvenes. Mientras tanto, aspectos como la experiencia de vivir con la enfermedad y la condición de género en la construcción de dichas representaciones, han sido abordados en menor medida. En este sentido, sería necesario seguir explorando como las nuevas condiciones de vida, en este caso el diagnóstico de seropositividad, pueden llevar a un desplazamiento o transformación en las representaciones sociales. Asimismo, sería oportuno que ante el aumento de infecciones en 
mujeres, se ahondará más sobre cómo influye la condición de género en los significados otorgados a la enfermedad. Estos argumentos sirven de justificación para el objetivo del presente estudio, el cuál es conocer la representación social que un grupo de mujeres con VIH ha elaborado sobre su actual estado de salud, ubicando los cambios y permanencias a partir de su diagnóstico y condición de género.

Con base en la revisión teórica, en este estudio se eligieron como meta categorías la muerte, sexualidad ilícita y cronicidad para aludir a los contenidos que definen la representación social del VIH. A su vez estos contenidos se clasificaron en hegemónicos, emancipados o polémicos siguiendo el planteamiento de Moscovici (1988) sobre las tres formas en que las representaciones pueden ser sociales. Se retomaron los criterios de clasificación de Rodríguez (2007) para el estudio cualitativo de los componentes de una r.s. (Anexo I).

Las interrogantes que se pretenden despejar son las siguientes: ¿supondrá el avance científico un cambio en la representación social del VIH en las mujeres mexicanas infectadas? y, de ser así ¿cómo serán esas representaciones sociales: hegemónicas, emancipadas o polémicas? ¿serán las mismas durante las diferentes fases de la enfermedad? y ¿qué papel juega la condición de género en los significados otorgados a la enfermedad?.

\section{Método}

\section{Diseño}

Descriptivo-interpretativo con una orientación metodológica de carácter cualitativo. La pertinencia de este diseño obedece a que el enfoque adoptado (desde la TRS) es el procesual, donde el ser humano es entendido como productor de sentidos, y se privilegian los contenidos como procesos discursivos determinados culturalmente (Banchs, 2000; Jodelet, 
1986). Al asumir este presupuesto ontológico, la teoría se sitúa dentro del paradigma hermenéutico-interpretativo, donde la aproximación cualitativa es la más recomendada (Guba y Lincoln, 1981; Jodelet, 1986).

\section{Participantes}

El muestreo se planteó como intencional y bajo el criterio de saturación, en donde el alcance del número de participantes se determinó como completo cuando una entrevista adicional ya no aportó nada nuevo con relación a la información ya obtenida (Guba y Lincoln, 1981).Esto ocurrió en la entrevista número doce. Es oportuno señalar que dentro de la investigación cualitativa comúnmente se trabaja con muestras pequeñas, sin embargo, los métodos cualitativos producen con mucha frecuencia resultados que se pueden suponer como ampliamente compartidos en una comunidad cultural o grupo social (Rodríguez, 2007).

Las participantes eran usuarias de dos centros de atención primaria especializados en VIH/SIDA, la Clínica Condesa y el Centro Ambulatorio para la Prevención y Atención de VIH/SIDA e Infecciones de Transmisión Sexual (CAPASITS), ambos ubicados en zonas urbanas de México, aunque casi la mitad de las participantes se desplazaban a estos centros desde zonas rurales. En la tabla 1, que se muestra a continuación, se encuentran los datos sociodemográficos y clínicos de la muestra estudiada. 
Tabla 1. Datos sociodemográficos y clínicos de las participantes

\begin{tabular}{|c|c|c|}
\hline & $\mathrm{N}$ & $\%$ \\
\hline \multicolumn{3}{|l|}{ Edad } \\
\hline $25-35$ & 7 & 58.3 \\
\hline $36-45$ & 3 & 25 \\
\hline $46-55$ & 1 & 8.3 \\
\hline$>50$ & 1 & 8.3 \\
\hline \multicolumn{3}{|l|}{ Centro de atención primaria } \\
\hline CAPASITS & 5 & 41.7 \\
\hline Clínica Condesa & 7 & 58.3 \\
\hline \multicolumn{3}{|l|}{ Lugar de residencia } \\
\hline Zona urbana & 7 & 58.3 \\
\hline Zona rural & 5 & 41.7 \\
\hline \multicolumn{3}{|l|}{ Edo. Civil } \\
\hline Casada/ Unión libre & 7 & 58.3 \\
\hline Divorciada & 1 & 8.3 \\
\hline Viuda & 4 & 33.3 \\
\hline \multicolumn{3}{|l|}{ Num. De descendientes } \\
\hline $1-2$ & 7 & 58.3 \\
\hline $3-5$ & 5 & 41.7 \\
\hline \multicolumn{3}{|l|}{ Escolaridad } \\
\hline Primaria & 3 & 25 \\
\hline Secundaria & 3 & 25 \\
\hline Bachillerato/Carrera Técnica & 4 & 33.3 \\
\hline Sin escolaridad & 2 & 16.7 \\
\hline \multicolumn{3}{|l|}{ Ocupación } \\
\hline Hogar & 6 & 50 \\
\hline Trabajo Doméstico & 2 & 16.7 \\
\hline Empleada & 1 & 8.3 \\
\hline Comerciante & 2 & 16.7 \\
\hline Trabajo Sexual & 1 & 8.3 \\
\hline \multicolumn{3}{|l|}{ Tiempo de Diagnóstico } \\
\hline 4 a 11 meses & 3 & 25 \\
\hline 1 a 5 años & 4 & 33.3 \\
\hline 6 a 10 años & 4 & 33.3 \\
\hline 11 a 15 años & 1 & 8.3 \\
\hline \multicolumn{3}{|l|}{ Se encuentra bajo tratamiento antirretroviral* } \\
\hline SI & 10 & 83.3 \\
\hline No & 2 & 16.7 \\
\hline \multicolumn{3}{|l|}{ Etapa enfermedad } \\
\hline Crónica & 10 & 83.3 \\
\hline Asintomática & 2 & 16.7 \\
\hline \multicolumn{3}{|l|}{ Vía de Transmisión } \\
\hline $\begin{array}{l}\text { Sexual (relaciones heterosexuales con hombres } \\
\text { seropositivos) }\end{array}$ & 12 & 100 \\
\hline \multicolumn{3}{|l|}{ Alguna vez ha recibido atención psicológica } \\
\hline Individual & 3 & 25 \\
\hline Grupos de auto apoyo & 2 & 16.7 \\
\hline No ha recibido & 7 & 58.3 \\
\hline
\end{tabular}

* Son tres los criterios para el inicio del tratamiento antirretroviral: 1) linfocitos CD4 menores de 350 células/mm3; 2) carga viral superior a las 30.000 copias por mililitro de sangre y, 3) aparición de enfermedades oportunistas. A su vez, la etapa de la enfermedad está asociada con estos criterios, y aquellas participantes que se encontraban en etapa asintomática eran las mismas que aún no habían iniciado tratamiento antirretroviral; por su parte aquellas en etapa crónica eran las mismas que sí estaban en tratamiento antirretroviral. 
Los criterios de inclusión fueron: a) ser mujer, b) mayor de 18 años, c) con diagnóstico confirmatorio de seropositividad superior a tres meses. Se descartó amujeres con algún problema de lenguaje debido a quela técnica empleada fue la entrevista.

\section{Instrumentos}

Se llevaron a cabo entrevistas en profundidad. La conveniencia metodológica de esta técnica obedeció a los siguientes criterios: 1) por tratarse de un estudio exploratorio, se requería ahondar en el tema, tarea difícilmente alcanzada a través de cuestionarios o instrumentos cerrados; 2) el lenguaje es el vehículo que permite acceder al universo simbólico y significante de los sujetos, a su realidad social constituida y constituyente (Jodelet, 1986) y; 3) otorga un lugar dinámico y de reconocimiento a la palabra del sujeto, que en el caso de las mujeres con VIH se hace necesario, dada su invisibilidad.

\section{Procedimiento}

A partir de la revisión documental se desarrolló una guía temática para la entrevista (Anexo II). Esta guía fue sometida a jueceo y se llevaron a cabo las correcciones pertinentes. Posteriormente, se contactó con los directores de los centros de atención referidos y se presentó el proyecto ante los respectivos Comités de Ética.

La convocatoria para participar en las entrevistas se hizo mediante un acercamiento previo con las usuarias de ambas instituciones, esto mediante la impartición de talleres enfocados en reducción de estrés por revelación del estatus a familiares y amigos (Flores, Chapa, Almanza y Gómez, 2011). Las usuarias que accedieron a participar en el estudio lo hicieron voluntariamente y previo consentimiento informado. Las entrevistas se desarrollaron en las instalaciones tanto del CAPASITS como de la Clínica Condesa. 


\section{Análisis}

Se realizó un análisis del contenido de las entrevistas (Bardin, 1982; Guba y Lincoln, 1981) y se utilizó el software N Vivo como auxiliar en la tarea de codificación. Durante un proceso de ida y vuelta sobre los datos, se buscó la saturación de los discursos, a fin de elaborar descripciones y generalizaciones cada vez más abstractas, de este proceso se obtuvieron 12 categorías: Deterioro corporal, Experimentación de la sintomatología, Miedo, Grupos de riesgo, Castigo, Mandatos de género, Atención en los servicios de salud, Diagnóstico tardío, Afrontamiento, Avances en la medicina, Contrarrestar el estigma, Una nueva oportunidad. Dichas categorías se agruparon en 3 meta categoríasque dieron cuenta de los contenidos de la representación social del VIH para la muestra estudiada.

En otras palabras, las categorías relacionadas con aspectos biológicos de la enfermedad que se circunscribían a una fase avanzada de esta (Deterioro corporal, Experimentación de la sintomatología, Miedo) se clasificaron en la meta-categoría muerte. Las categorías en donde se destacaban aspectos de orden moral vinculados a la principal forma de transmisión del VIH (Grupos de riesgo, Castigo, Mandatos de género, Atención en los servicios de salud, Diagnóstico tardío) se clasificaron en la meta categoría sexualidad ilícita. Por su parte, aquellas categorías en donde se develaba el actual carácter crónico y tratable de esta enfermedad (Afrontamiento, Avances en la medicina, Contrarrestar el estigma, Una nueva oportunidad) se categorizaron en la meta categoría cronicidad.

Como se mencionó anteriormente, para acceder a los contenidos de la representación social del VIH se retomaron los criterios de clasificación que Rodríguez (2007, p. 178-179) propone para el estudio cualitativo de los componentes de una representación social. Desde este abordaje se entiende que los tres contenidos (hegemónicos, emancipados y polémicos) 
pueden coexistir en grados diversos dentro de una misma representación social, siendo la mayor presencia de alguno de estos lo que permitirá identificar el sistema holístico de la representación en el grupo estudiado. ${ }^{2}$ Es decir, sí los contenidos eran colectivamente compartidos, legítimos y asumidos como "naturales" a través de afirmaciones poco susceptibles a la discusión social, se clasificaron como hegemónicos. Si en estos contenidos se identificaba la fuente de autoridad social que los sustentaba y se trataba de significados que legitimaran la aceptación de ciertos contenidos culturales, pero a su vez limitaran su impacto dentro de la muestra estudiada, se clasificaron como emancipados. Si por el contrario, eran contenidos discutidos abiertamente, deliberados, conscientes, y con tendencia a socavar la validez universal construida por los contenidos normativos imperantes en la sociedad, para hacer valer nuevos contenidos o excepciones de significación o práctica, se clasificarían como polémicos (Anexo I).

Para asegurar la validez y confiabilidad de los resultados (Guba y Lincoln, 1981; Morse, Barret, Mayan, Olson y Spiers, 2002)se siguieron los siguientes lineamientos: 1) saturación de la información, 2) jueceo del instrumento (guía de entrevista), 3) codificación simultánea, 4) discusión de las interpretaciones con otros investigadores y/o expertos en el tema, 5) uso de transcripciones textuales de las entrevistas para respaldar los significados e interpretación presentados en los resultados del estudio.

\footnotetext{
${ }^{2}$ Haciendo una analogía con el enfoque estructural (Abric, 1993), los contenidos hegemónicos serían el equivalente al núcleo duro de la representación social y los contenidos emancipados y polémicos serían la periferia.
} 


\section{Resultados}

En la tabla 2, se encontrarán desglosadas en la primera columna de lado izquierdo, las tres meta categorías que fueron identificadas como los contenidos que definen la representación social del VIH para la muestra estudiada: muerte, sexualidad ilícita y cronicidad. En la siguiente columna, se señala el tipo de contenido de la representación aludiendo únicamente a hegemónicos y emancipados, que fueron los identificados en el estudio. En la tercera columna se señalan las 12 categorías a partir de las cuáles se definieron las meta categorías. Y finalmente, en la cuarta columna se presentan algunas frases de las entrevistas

Tabla 2. Clasificación de los contenidos de la representación social del VIH

\begin{tabular}{|c|c|c|c|}
\hline Meta categoría & Contenido & Categorías & Frases \\
\hline \multirow{4}{*}{ Muerte } & \multirow{4}{*}{ Hegemónico } & \multirow{3}{*}{$\begin{array}{l}\text {-Experimentar la } \\
\text { sintomatología }\end{array}$} & $\begin{array}{l}\text { "El mundo se me vino encima en ese momento (cuando le } \\
\text { dieron el diagnóstico) como yo había ido a que me sacaran } \\
\text { la sangre yo había ido antes había visto a un muchacho } \\
\text { joven parecía una calaverita y sin pelo, si nada, en ese } \\
\text { momento me refleje en él y me dijeron todo lo que me iba } \\
\text { a salir y yo sentía que mis manos tenían no sé qué, me veía } \\
\text { toda mal..." } \\
\text { "Mi etapa llegó tan fuerte que yo oía sirenas y era una } \\
\text { negación horrible. O sea, yo oía sirenas y ya me hacía en } \\
\text { una cama de hospital entubada con veinte mi } \\
\text { mangueras... ". }\end{array}$ \\
\hline & & & $\begin{array}{l}\text { “ }[\ldots] \text { tengo una de mis hermanas que ella es muy sensible } \\
\text { cuando supo eso (su diagnóstico de seropositividad) pues le } \\
\text { cayó muy de sopetón lo que me estaba pasando y este, como } \\
\text { se dice se le vino a la mente lo que a todo mundo: que yo } \\
\text { me iba a morir." }\end{array}$ \\
\hline & & & $\begin{array}{l}\text { "Cuando ya empecé a sentir los síntomas ese era mi } \\
\text { miedo ¿no?, que no iba a llegar a esa edad, y este y si } \\
\text { preparé un vaso con veneno para ratas y me lo tomé..." }\end{array}$ \\
\hline & & -Miedo & $\begin{array}{l}\text { "[...] pero hasta la fecha todavía sigo así como con tantito } \\
\text { que me enfermó digo "Ay Dios mío" o me da miedo..." }\end{array}$ \\
\hline
\end{tabular}




\begin{tabular}{|c|c|c|c|}
\hline Meta categoría & Contenido & Categorías & Frases \\
\hline \multirow{8}{*}{ Sexualidad ilícita } & \multirow{8}{*}{ Hegemónico } & -Grupos de riesgo & $\begin{array}{l}\text { "Entonces dicen que ellas no conocían nada sobre el tema } \\
\text { (compañeras del grupo de auto apoyo), pero sí tenían un } \\
\text { idea de que el VIH, como tiene que ver con mucha } \\
\text { situaciones de sexualidad, que era como algo asociado } \\
\text { prostitutas, a homosexuales, etc." }\end{array}$ \\
\hline & & -Castigo & $\begin{array}{l}\text { "Cuando se murió este niño (se refiere a su vecino) "ay ya } \\
\text { se murió el jotito sidoso" que no se que tanto..." }\end{array}$ \\
\hline & & $\begin{array}{l}\text { - Mandatos de } \\
\text { género }\end{array}$ & $\begin{array}{l}\text { “Pues porque estoy pasando esta situación? o sea, una } \\
\text { mala mujer nunca fui... o sea eh, y luego veo, de hecho } \\
\text { tengo una vecina que anda con los borrachos ahí tomando, } \\
\text { se acuesta con uno, se acuesta con otro... porque me está } \\
\text { pasando a mi esta situación que yo no he vivido así, ella sin } \\
\text { embargo, que se da la libertad de andar con uno, con otro y } \\
\text { con otro... no se ha visto en una situación así o sea...” }\end{array}$ \\
\hline & & -Atención en & $\begin{array}{l}\text { "Yo no siento que haya hecho algo tan malo o tan grave } \\
\text { para que yo esté pagando esto..." }\end{array}$ \\
\hline & & $\begin{array}{l}\text { los servicios de } \\
\text { salud }\end{array}$ & $\begin{array}{l}\text { "La ginecóloga que me tocó aquí (se refiere al } \\
\text { CAPASITS), desde un principio que yo vine a hacerme mi } \\
\text { chequeo para el embarazo primero me puso una regañiza, } \\
\text { terrible..." }\end{array}$ \\
\hline & & -Diagnóstico tardío & $\begin{array}{l}\text { "Fuimos con otro doctor y le dijeron (a su esposo) que tenía } \\
\text { infección (una infección de transmisión sexual) y yo me } \\
\text { acuerdo que le dijo el doctor que con quien se había } \\
\text { metido..." }\end{array}$ \\
\hline & & & $\begin{array}{l}{[\ldots] \text { una enfermera antes de darme los resultados, me preparó }} \\
\text { y me dijo que si yo ino había engañado a mi } \\
\text { esposo?..." }\end{array}$ \\
\hline & & & $\begin{array}{l}\text { "A mí me diagnosticaban leucemia y cuanta cosa se les } \\
\text { antojaba yo tenía y cuando vieron que no era nada de eso } \\
\text { me dijeron: ¿sabes qué? que te vamos a hacer una prueba } \\
\text { de VIH, ite la has hecho?"...". }\end{array}$ \\
\hline
\end{tabular}




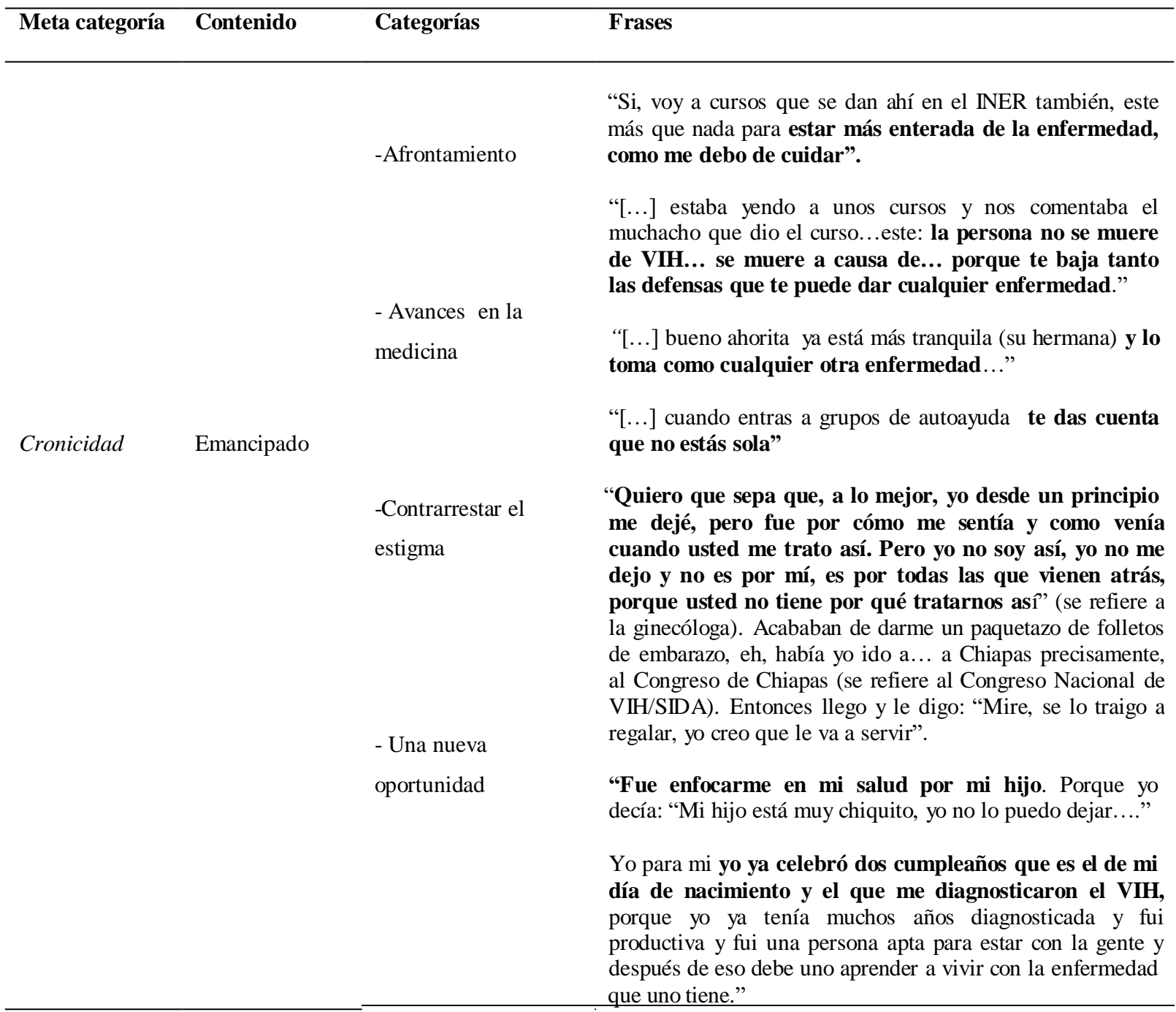

Muerte

Destacó en primer lugar una asociación de VIH igual a muerte en el discurso de todas las participantes (significado colectivamente compartido), lo que evidenció su carácter hegemónico. Las entrevistadas hicieron referencia a temas como el deterioro corporal(delgadez extrema, palidez, sarcoma de Kaposi, etcétera), la sintomatología experimentada durante la fase aguda de la enfermedad y el miedo a morir. 
A través de los relatos, se pudieron identificar como elementos que dieron sustento a este contenido: 1) el trato sensacionalista y amarillista que se le dio a esta enfermedad durante los primeros años de su aparición, 2) las muertes que cobró esta epidemia antes del desarrollo del TAAR y 3) la experimentación de la sinto matología durante la fase aguda.

El tipo de información (sensacionalista y amarillista) que circulo en los medios masivos de comunicación, principalmente durante la década de los ochenta y principios de los noventa del siglo pasado, coincidió con la adolescencia o juventud de las participantes, quienes recordaron que fue a través de la televisión y de los rumores que circulaban en su medio próximo (familia y/o vecinos) de donde obtuvieron sus primeras nociones acerca de la enfermedad, previo diagnóstico. Cabe destacar que en ambos escenarios esta enfermedad era retratada como terrible y mortal.

La muerte apareció como una posibilidad casi inminente en dos momentos: al recibir el diagnóstico y al presentarse alguna crisis de salud. En este sentido, la fase de la enfermedad marcó una diferencia. Para quienes se encontraban en fase asintomática, o sea para el16.7\%, esta posibilidad aunque existente se hacía menos evidente en su discurso -a excepción de cuando recibieron el diagnóstico-,pues no habían experimentado ningún síntoma, sin embargo, señalaron que el no saber que les iba a suceder cuando iniciaran el TAAR, les generaba ansiedad e incertidumbre por el futuro. En el caso de quienes fueron diagnosticadas durante una fase aguda y al momento de la entrevista se encontraban en fase crónica, es decir el $83.3 \%$, la experiencia de sentirse mal, de experimentar los síntomas ya fuera de la misma enfermedad o de los efectos secundarios del tratamiento antirretroviral, hicieron más palpable la posibilidad de morir, llevándolas a periodos de depresión. Incluso un $33.3 \%$ coincidió en que pensó o intentó suicidarse como respuesta a la experimentación de dicha sintomatología. Tanto en asintomáticas (16.7\%) como en aquellas en fase crónica $(83.3 \%)$, fue recurrente el discurso 
sobre el miedo a morir y dejar en el desamparo a sus seres queridos, principalmente a sus hijas e hijos.

\section{Sexualidad ilícita}

Esta meta categoría fue clasificada como un contenido hegemónico de la representación social del VIH, dado que prevalecieron y fueron ampliamente compartidos por la muestra estudiada, aspectos de orden moral vinculados a la enfermedad cuyo carácter socialmente elaborado fue invisible y poco cuestionado. En este sentido, el conocimiento que tenían el 75\% ( $\mathrm{N}=9)$ de las entrevistadas sobre el virus, antes de conocer su diagnostico, se restringía a concebirla como una enfermedad mortal que se adquiere por relaciones sexuales y exclusiva de ciertos grupos como homosexuales, drogadictos, prostitutas o personas promiscuas. El otro 25\% (N=3) señaló que tenía información sobre el carácter biológico de la infección y todas las formas de transmisión desde antes de conocer su estatus serológico.

En el caso de aquellas en las que predominó el discurso sobre los "grupos de riesgo" (75\%), el sentimiento de distancia frente al VIH fue mayor y dificultó que se hicieran revisiones médicas de rutina que incluyeran la prueba de detección del virus, a pesar de intuir o saber que sus parejas sostenían relaciones sexuales con otras mujeres u hombres. Solamente el $16.7 \%$ manifestó haber acudido por decisión propia a realizarse dicha prueba.

A la concepción sobre "grupos de riesgo" se superpusieron otras representaciones fuertemente arraigadas en el pensamiento social (hegemónicas) que son estructuradas a partir del género y que dictan lo que es lícito e ilícito en el ejercicio de la sexualidad. Por ejemplo, se encontró que la promiscuidad femenina fue sancionada más severamente que la masculina, porque la primera transgrede los mandatos de género sobre la represión del deseo sexual. Así, la 
diferenciación "otras" y "yo", operó bajo la polarización "buena/mala", producto de un largo proceso de aleccionamiento del género reforzado por todas las instituciones sociales particularmente la Familia, la Escuela y la Iglesia. En el caso de las entrevistadas, se pudo advertir que dicho aleccionamiento no sólo fue a través de la violencia simbólica del orden genérico, sino también a través de la violencia física y sexual, la cual estuvo presente en el $58.3 \%$ de la muestra.

Desde estos márgenes, la infección fue vista como un castigo por el ejercicio de una sexualidad "desviada", marcando diferencias dependiendo de la ubicación en la polarización buena/mala. Aquellas informantes que antes de infectarse sólo tuvieron una pareja sexual y que fue con la que se casaron o formaron una familia (50\%), es decir quienes "cumplieron" las normas dictadas para su sexo, experimentaron más coraje y se señalaron como víctimas y por tanto no merecedoras de un castigo así. Mientras aquellas que tuvieron más de una pareja sexual antes de infectarse (50\%), si bien manifestaron los mismos sentimientos, estos fueron menos intensos, sobre todo si desconocían quien las infectó; en cambio, expresaron más sentimientos de culpa y se ubicaron como merecedoras del castigo, si una nueva pareja y/o sus descendientes resultaron seropositivos, a pesar de reconocer que no lo hicieron deliberadamente ya que desconocían su estatus serológico.

Se pudo develar también que este contenido representacional acerca de la sexualidad ilícita, no sólo estuvo presente en las entrevistadas, sino también en algunos profesionales de la salud que las atendieron a ellas o a sus parejas, muestra de ello es que el $66.7 \%$ coincidió en que hubo un largo proceso de ambulantaje institucional, exámenes y revisiones médicas antes de llegar a un diagnóstico certero para ellas o sus parejas. Por tanto, la prueba de detección de VIH, vino a constituir la última cadena del eslabón a pesar de que los síntomas presentados por ellas o sus parejas sugirieran la aplicación de esta. Con base en estos hallazgos, se pudo suponer 
que las evaluaciones médicas y diagnósticos no fueron neutros, contuvieron una carga moral que interfirió en el tratamiento oportuno. Ejemplo de esto fue lo que sucedió a las parejas de las entrevistadas viudas (33.3\%), quienes fueron diagnosticados ya en fase SIDA y con complicaciones severas de salud, por lo que fallecieron poco tiempo después.

\section{Cronicidad}

En esta meta categoría, se pudieron encontrar elementos que permitieron ubicarla como un contenido emancipado de la representación social del VIH, principalmente porque sólo estuvo presente en algunas mujeres que se encontraban en tratamiento antirretroviral, en fase crónica, con mayor tiempo de haber sido diagnosticadas y que habían acudido a algún tipo de apoyo psicológico (terapia individual o grupal). Asimismo, porque a través de los relatos, los médicos fueron identificados como fuente de autoridad del discurso sobre el carácter crónico de la enfermedad.

De esta manera, se encontró que si bien el TAAR ha permitido al $83.3 \%$ de las entrevistadas estar en una fase crónica y prolongar su esperanza de vida, la vivencia de la enfermedad va más allá y supone un proceso activo de gestión que implica modificaciones en su rutina, relaciones interpersonales, expectativas, deseos, etcétera. A su vez estos cambios han repercutido en el otorgamiento de nuevos significados del VIH, en este caso el de cronicidad, el cual estuvo presente en el 50\% de la muestra. En este porcentaje de la muestra, también se pudieron detectar estrategias de afrontamiento positivas como: búsqueda de información fiable, adherencia al tratamiento antirretroviral, exigencia de derechos al personal médico e involucramiento en actividades para contrarrestar el estigma y la discriminación. 
Otro punto que cabe resaltar, es que a la par de este desplazamiento en los significados otorgados a la enfermedad, un 33.3\% logró cuestionarse normas sobre su rol de género y las implicaciones de estas en la adquisición de la infección. Estos cuestionamientos les han permitido asumirse como sujetos con derechos y generar un proyecto de vida propio (retomar sus estudios, ejercer su sexualidad libremente, viajar, salir con amistades, trabajar, etc.) más allá de circunscribirlo a su papel en tanto madre, esposa o hija. En este sentido, la fase de la enfermedad (crónica), mayor tiempo de diagnóstico, el lugar de residencia (zona urbana), el acceso a servicios médicos de calidad, el soporte social, el estado civil (viudez), menor presencia de violencia y la relación de proximidad con pares (grupos de auto apoyo), parecen ser elementos que influyeron en el desplazamiento de los contenidos de la representación social en el grupo estudiado.

Por otra parte, en aquellas entrevistadas en que no se visibilizó una ruptura o desplazamiento en torno a su condición de género (66.7\%), se pudieron detectar las siguientes situaciones: pocas oportunidades en el ámbito laboral marcados por empleos informales y poco remunerados $(50 \%)$, bajo nivel educativo (66.7\%), poco acceso a información fiable sobre salud sexual y reproductiva, presencia de violencia en diversos escenarios $(58.3 \%) \mathrm{e}$ infectadas principalmente en el espacio conyugal o el concubinato (83.3\%). Otras cuestiones que se pudieron detectar a través de los relatos, fueron: anteposición del cuidado propio al de la pareja e hijos, fallas en la adherencia terapéutica por precariedad económica (trasladarse de su lugar de residencia rural al urbano), pocas o nulas redes de apoyo, violencia derivada del estigma sobre su condición de salud (comunitario, familiar y en los servicios de salud), presencia de trastornos psicológicos (ansiedad y depresión) como resultado de este escenario, con el consecuente detrimento en su sistema inmunológico. 


\section{Discusión}

El presente trabajo tuvo como objetivo conocer la representación social que un grupo de mujeres con VIH ha elaborado sobre su enfermedad, ubicando los cambios y permanencias a partir de su diagnóstico y condición de género. En este sentido, se pudieron corroborar los hallazgos de otras investigaciones que han reportado como elementos centrales de esta representación: la muerte y la sexualidad (Abreu et al., 2012; Chong et al., 2007; Flores y De Alba, 2006; Fonseca, 2009; Giacomozzi y Vizeu, 2004; Jofré et al., 2005; Flores y Leyva, 2003; Madeira 1998; Morin, 1994). En concordancia con Pereira y Arruda (2005), se encontró como contenido emancipado (o periférico desde una aproximación estructural) la cronicidad, pudiéndose establecer diferencias de acuerdo a la fase de la enfermedad y una negociación de significados a partir de la experimentación de la sintomatología (Herzlich y Pierret, 1988; Jodelet, 2004; Pierret, 2000).

En cuanto a la interrogante planteada acerca de sí los cambios científicos llevan necesariamente a cambios a nivel representacional, la asociación de la enfermedad a una sexualidad ilícita, particularmente ejemplificada a través del discurso sobre "grupos de riesgo" (trabajadoras sexuales, homosexuales, drogadictos, promiscuos), permitió dar cuenta de la vigencia del sistema de normas y valores sobre género y sexualidad arraigados en el pensamiento social a pesar de los avances científicos que se han dado en el campo de la salud. Este hallazgo permite ver que estos avances científicos no necesariamente llevan a cambios a nivel representacional, ya que la dimensión de valor se orienta principalmente de acuerdo a las reglas sociales y culturales cuya racionalidad es social y no científica como han señalado Wagner y Hayes (2011). La construcción de esta representación y su permanencia en diversos grupos (incluidos profesionales de la salud), momentos y contextos da cuenta de su carácter 
hegemónico, cuya función es normativa y delimita la identidad social (Flores y De Alba, 2006; Fonseca, 2009; Horton y Aggleton, 1989).

La muerte como otro contenido hegemónico de la representación del VIH en la muestra estudiada, está relacionada con la naturaleza biológica de la enfermedad, sobre todo con la severidad y la acción degenerativa que se manifestó ante la falta de tratamiento durante la primera década de su aparición (Fonseca, 2009; Morin, 1994). De ahí que antes de saber su diagnóstico -e incluso después- las entrevistadas compartían esta representación, difundida principalmente a través de la información que circulaba en los medios masivos de comunicación y su medio próximo (Flores y Leyva, 2003; Petracci, 1997).

Respecto a los contenidos emancipados, en este estudio sólo se detectó uno, el de cronicidad. Se pudo identificar que la fuente de autoridad que sustentaba este discurso provenía del ámbito médico. No obstante, este contenido mostró un impacto limitado, pues solamente se encontró presente en un segmento de la muestra estudiada. Es decir, fue más fácil que las mujeres que llevaban más tiempo diagnosticadas y que se encontraban bajo tratamiento antirretroviral, hubieran aceptado su condición serológica y por ende se sintieran identificadas con este discurso médico (Pereira y Arruda, 2005); mientras que las asintomáticas, que aún no iniciaban tratamiento antirretroviral, no habían logrado incorporar ese contenido.

El abordaje cualitativo del sistema representacional propuesto por Rodríguez (2007), permitió asir teóricamente como el grupo estudiado elaboró y transformó sus contenidos representacionales ante situaciones de crisis o cambios en las condiciones de vida. En este tenor, se pudo corroborar la coexistencia de elementos contradictorios en la representación social, pues aún cuando se encontró presente en el campo representacional lo crónico de la enfermedad, las crisis de salud reactivaban en las entrevistadas pensamientos sobre la muerte, ratificando 
con ello que las diferencias radicales entre la experiencia y la representación llevan al sistema a negociarse nuevamente de manera individual y colectiva como lo han señalado Wagner y Hayes (2011).

Cabe destacar que pese a lo controversial que ha sido este objeto de estudio, no se registraron contenidos polémicos, es decir no se encontraron antagonismos ni rupturas radicales en los significados otorgados al VIH en la muestra estudiada. Esto puede obedecer a que los temas a los que ha estado vinculada esta enfermedad, son objetos con una larga historia cultural como el género, la sexualidad y la muerte; mientras que el VIH/SIDA lleva presente solamente tres décadas en nuestro país. Lo anterior, no significa que estos contenidos no puedan estar presentes en otros grupos, principalmente en grupos pro derechos o personas situadas en contextos menos coercitivos y/o desiguales.

Respecto al papel que juega la condición de género en los significados otorgados a la enfermedad, los resultados mostraron patrones discursivos claramente relacionados con las asimetrías entre hombres y mujeres que, como se ha reportado en otras investigaciones (véase Abreu et al., 2012; Allen y Torres, 2008; Enria et al., 2010; Herrera y Campero, 2002; Théodore et al., 2004; Torres et al., 2010), constituyen un obstáculo en materia de prevención y atención en la población femenina, dando como resultado un aumento en el número de infecciones y la detección tardía del VIH, situación que se hizo manifiesta en la mayoría de los relatos. Destacaron (pese a ser una muestra pequeña) las coincidencias respecto a las condiciones de vulnerabilidad para las mujeres en la adquisición del VIH reportadas en la literatura (Allen y Torres, 2008; Abreu et al., 2012; Giacomozzi y Vizeu, 2004; Herrera y Campero, 2002; Théodore et al., 2004; Torres et al., 2010),lo que refleja que en nuestro país, pese a la mayor presencia de las mujeres en el ámbito público, permanece una estructura asimétrica que imposibilita que estas sean plenamente reconocidas como sujetos de derecho. 
Finalmente, se pudieron detectar dos situaciones tras la llegada del VIH: 1)reforzamiento o agudización de la condición de la vulnerabilidad de género y, 2) Una resignificación sobre su condición de salud y posicionamiento de género que les ha permitido ir cuestionando representaciones hegemónicas relativas al deber ser femenino y al VIH, trabajo de reconstrucción que las ha llevado entre otras cosas a hacer frente al estigma y discriminación, afrontar positivamente la enfermedad y elaborar un proyecto de vida priorizando sus necesidades. Ambas posibilidades estuvieron vinculadas con mayor o menor acceso a recursos sociales, materiales y culturales, mostrando así la íntima relación que guarda lo psicológico o cognitivo y lo social en la construcción de significados (Jodelet, 1986; Moscovici, 1979).

\section{Comentarios finales}

A diferencia de paradigmas positivistas en la psicología, desde la teoría de las representaciones sociales y la perspectiva de género, se rescata el papel de agencia de los sujetos, en este caso de las participantes como co-constructoras de significados acerca de su enfermedad; permitiendo por un lado reconocer el papel de la experiencia corporal en estos significados y por otro, visibilizando de qué manera estos significados y prácticas se circunscriben a las condiciones históricas, políticas sociales y culturales.

Se recomienda para futuras investigaciones llevar a cabo diversas comparaciones entre grupos de mujeres con VIH con el objetivo de poder establecer diferencias más precisas en cuanto a posicionamiento social y contenidos representacionales. En este sentido, sería oportuno incluir a mujeres con una larga trayectoria dentro del activismo, para rescatar más nítidamente los procesos de ruptura. Otra sugerencia es llevar a cabo comparaciones entre resultados provenientes de distintas aproximaciones en el estudio de las representaciones 
sociales, así como emplear otros métodos de recolección de datos para dar mayor validez a los resultados aquí reportados.

Finalmente, sería importante considerar que no es necesario esperar a que las mujeres se conviertan en un grupo clave (epidemiológicamente hablando) para voltear a verlas. Se hace urgente realizar más investigación en este sector poblacional con miras a desarrollar estrategias eficaces y pertinentes a la realidad sociocultural, tanto en prevención primaria como positiva. 


\section{Referencias}

Abreu, L., Santos, M., Freitas, J y Maria da Nóbrega, S. (2012).Vulnerabilidade de mulheres em uniao heterosexual estável á infeccao pelo HIV/AIDS: estudo de representacoes sociais. Rev Esc Enferm USP, 46 (2), 349-355.

Abric, J.C. (1993). Central system, pheriperal system. Roles and dynamic of social representations, Papers on Social Representations, 2 (2), 75-78.

Allen, B. y Torres, P. (2008). Género, poder y VIH/SIDA en la vida de las mujeres mexicanas: prevención, atención y acciones prioritarias. En J. Córdova, S. Villalobos, S. Ponce de León y J. Valdespino (Eds.). 25 Años de SIDA en México. Logros, desaciertos y retos (pp. 257-287). México: Instituto Nacional de Salud Pública.

Banchs, M. A. (2000). Representaciones sociales, memoria social e identidad de género, Akademos, 2(1), 59-76.

Bardin, L. (1982). Análisis de Contenido, Barcelona: Akal.

Centro Nacional para la Prevención y Control del VIH/SIDA (2013). Informe de Vigilancia Epidemiológica de Casos de VIH/SIDA en México. Registro Nacional de Casos de SIDA. Actualización al 30 de Junio del 2013. México. Recuperado el 12 de octubre del 2013,

en http://www.censida.salud.gob.mx/descargas/ungass/Informe_Narrativo_2012_y_ANE XOS_I_IV.pdf

Chong, F., Torres, T. y López, B. (2003). Las representaciones sociales sobre el VIH en jóvenes de tres ciudades mexicanas. En R. Tinoco, M. Martínez y A. Evangelista 
(Eds.).Compartiendo saberes sobre VIH en Chiapas (pp. 141-165). Comitán: El Colegio de la Frontera Sur.

Enria, G., Fleitas, M. y Staffolani, C. (2010).Programa de salud y género. Mujeres con VIH/SIDA. Estudios Sociales, 18(35), 276-292.

Flores, F. Chapa, A., Almanza, M. y Gómez, A. (2011). Adaptación del programa de intervención "Relaciones Saludables" a grupos de México que viven con el virus de la inmunodeficiencia humana. Acta Psiquiátrica y Psicológica de América Latina, 57 (1), 29-38.

Flores, F. Leyva, R. (2003). Representación social del SIDA en estudiantes de la Ciudad de México. Salud Pública Mex, 45 (Supl. 5), 624-631.

Flores, F. y De Alba, M. (2006). El sida y los jóvenes: un estudio de representaciones sociales. Salud Mental, 29 (3), 51-59.

Fonseca, P. (2009). Representaciones sociales del VIH/SIDA en jóvenes con y sin VIH en la ciudad de Bogotá, D.C: Aportes para la comprensión de sus significados y prácticas. Universidad Nacional de Colombia, Bogotá, Colombia.

Giacomozzi, A. y Vizeu, B. (2004). Eu confio no meu marido: estudo da representação social de mulheres comparceiro fixo sobre prevenção da AIDS. Psicología: Teoría e Práctica, 6 (1),31-44.

Grimberg, M. (2009). Sexualidad, experiencias corporales y género: un estudio etnográfico entre personas viviendo con VIH en el Área Metropolitana de Buenos Aires, Argentina. Cadernos de Saúde Pública, 25 (1), 133-141. 
Goodwin, R., Kwiatkowska, A., Realo, A., Kozlova, A. Nguyen, L. y Nizharadze, G. (2004). Social representations of HIV/AIDS in five Central European and Eastern European countries: a multidimensional analysis. AIDS CARE, 16 (6), 669-680.

Guba, E., Lincoln, Y.S. (1981). Effective evaluation: Improving the usefulness of evaluation results through responsive and naturalistic approaches. San Francisco: Jossey-Bass.

Herzlich, C. y Pierret, J. (1988). De ayer a hoy: construcción social del enfermo. Cuadernos Médicos Sociales, 43, 21-30.

Herrera, C. y Campero, L. (2002). La vulnerabilidad e Invisibilidad de las mujeres ante el VIH/SIDA: constantes y cambios en el tema, Salud Pública de México, 44 (6), 554564.

Horton, M. y Aggleton, P. (1989). Perverts, inverts and experts: The cultural production of an AIDS research paradigm. En P. Aggleton, G. Hart y P. Davies (Eds.) Social representations, social practice (pp. 74-100).Londres: Falmer Press.

Jodelet, D. (2004). Experiencia y representaciones sociales. En E. Romero (Ed.).Representaciones sociales, atisbos y cavilaciones del devenir de cuatro décadas (pp. 85-116). México: Benemérita Universidad Autónoma de Puebla.

Jodelet, D. (1986). La representación social: fenómeno, concepto y teoría. En S. Moscovici (Ed.). Psicología social: pensamiento y vida social (pp. 469-494).Barcelona: Paidós.

Joffe, H. (1995). Social representations of AIDS: towards encompassing issues of power. Papers on Social Representations, 4 (1), 29-49. Recuperado el 23 de agosto de 2011, en http://www.psr.jku.at/PSR1995/4_1995Joffe.pdf 
Jofré, M., Marin, L. y Yuli, M. (2005). La representación social sobre el SIDA en profesionales de la salud. Psicología y salud, 15 (1), 13-23.

Konstantinidis, A. y Cabello, M.L. (2008). La notificación del diagnóstico y las primeras reacciones de personas infectadas por el virus VIH. Un estudio cualitativo realizado en el área metropolitana de Monterrey, N.L. Perspectivas Sociales, 10 (1), 87-112.

Madeira, M. C. (1998). A confiança afrontada: representação social da AIDS para jovens. En M. Madeira y D. Jodelet (Eds.). AIDS e representações sociais: à busca de sentidos (pp. 47-73).Natal: EDUFRN.

Mendes, A. y Kornblit, A. (1997). Actitudes hacia el SIDA en estudiantes secundarios. En A. Kornblit (Comp.). SIDA y Sociedad (pp. 91-105). Buenos Aires: Espacio.

Morin, M. (1994). Entre representaciones y prácticas: el SIDA, la prevención y los jóvenes. En J. Abric (Comp.).Prácticas sociales y representaciones (pp. 195-214). México: Ediciones Coyoacán.

Morse, J., Barret, M., Mayan, M., Olson, K. Y Spiers, J.(2002).Verification strategies for establishing reliability and validity in qualitative research. International Journal of Qualitative Methods, 1 (2) ,18-36. Recuperado el 9 de enero de 2014, en http://www.ualberta.ca/ ijqm

Moscovici, S. (1979). El psicoanálisis, su imagen y su público. Buenos Aires: Editorial Huemul.

Moscovici, S. (1988). Notes towards a description of social representations. European Journal of Social Psychology, 18, 211-250. 
Oliveira, D. y Lessa da Costa, T. (2007). A zona muda das representações sociais sobre o portador de HIV/AIDS: elementos normativos e contra normativos do pensamento social. Psicología: Teoría e Práctica, 9 (2), 73-91.

Pereira, G. y Arruda, A. (2005). Representaciones sociales de la seropositividad y su relación con la adherencia al tratamiento. Ciencia e Saúde Coletiva, 10(1), 151-162.

Petracci, M. (1997). La representación social del SIDA en la ciudad de Buenos Aires. En A. Kornblit (Comp.).SIDA y Sociedad (pp. 77-89). Buenos Aires: Espacio.

Pierret, J. (2000). Vivir con VIH en un contexto de enfermedad crónica: aspectos metodológicos y conceptuales. Cuad Med Soc, 77, 35-44.

Rodriguez, T. (2007). Sobre el estudio cualitativo de la estructura de las representaciones sociales. En T. Rodríguez y M. L. García (Comps.) Representaciones sociales. Teoría e investigación (pp. 157-190). Guadalajara: Universidad de Guadalajara.

Secretaria de Salud y Centro Nacional para la Prevención y Control del VIH/SIDA (31 de marzo de 2013). Informe Nacional de Avances en la Lucha contra el SIDA. Periodo reportado: Enero 2010-Diciembre 2011. Recuperado el 20 de enero del 2014, enhttp://www.unaids.org/en/dataanalysis/knowyourresponse/countryprogressreports/2 012countries/Informe\%20Narrativo\%202012_Mexico20120625.pdf

Théodore, F., Gutiérrez, J., Torres, P., Luna, G. (2004). El sexo recompensado: una práctica en el centro de las vulnerabilidades (ITS/VIH/SIDA) de las jóvenes mexicanas. Salud Pública Mex, 46(2), 104-112. 
Torres, P., Zarco, A. y Allen-Leigh, B. (2010). Prevención. En M. Torres (Ed.).Mujeres, adolescentes y niñas mexicanas: una mirada comprensiva en torno al VIH y al SIDA (pp.52-101). México: Ángulos del Sida.

Wagner, W. y Hayes, N. (2011). El discurso de lo cotidiano y el sentido común. Barcelona: Anthropos. 


\section{ANEXOS}

Anexo I.

Criterios para la clasificación de contenidos representacionales de acuerdo a Rodríguez (2007)

\begin{tabular}{|c|c|}
\hline Contenido & Criterios de definición \\
\hline Hegemónico & $\begin{array}{l}\text { Colectivamente compartidos, legítimos y menos susceptibles a la discusión } \\
\text { social. } \\
\text { Se hacen visibles a través de enunciados afirmativos y descriptivos que } \\
\text { constatan, que explican significados sin duda de su existencia. } \\
\text { Son creencias simbólicamente poderosas que se asumen como "naturales", } \\
\text { donde su carácter socialmente elaborado es invisible. }\end{array}$ \\
\hline Emancipado & $\begin{array}{l}\text { Creencias y valores que sostienen grupos sociales específicos, compartidas } \\
\text { en la escala del grupo social en un momento dado. } \\
\text { Parten de la fuente de autoridad de la sociedad donde las personas } \\
\text { identifican la fuente o autoridad social que los sustenta. } \\
\text { Su fuerza simbólica se circunscribe a ciertas circunstancias sociales. } \\
\text { Se trata de significados que legitiman la aceptación de ciertos contenidos } \\
\text { culturales, pero a su vez limitan su impacto a ciertos grupos sociales o } \\
\text { comunidades culturales. }\end{array}$ \\
\hline Polémico & $\begin{array}{l}\text { Son aquellos que son discutidos abiertamente dentro de un grupo social; } \\
\text { son contenidos que se asumen con cargas de relativismo, los cuales } \\
\text { generan dudas, críticas, o particularización de significados. } \\
\text { Son contenidos que amenazan las regiones de la representación más } \\
\text { sólidas en términos de reconocimiento, aceptación y legitimidad. Esta } \\
\text { clase de contenidos son deliberados, conscientes, y tienden a socavar la } \\
\text { factualidad o validez universal construida por los contenidos } \\
\text { hegemónicos, así como los contenidos normativos construidos dentro del } \\
\text { grupo social, para hacer valer nuevos contenidos o excepciones de } \\
\text { significación o práctica. }\end{array}$ \\
\hline
\end{tabular}




\section{Anexo II.}

\section{Guía Temática}

Explicitar el propósito de investigación, haciendo énfasis en la confidencialidad (presentar y explicar el consentimiento informado) y agradeciendo la disposición a participar. Se debe aclarar que tal vez se necesiten más sesiones para ahondar más en algún tema y para contrastar las interpretaciones hechas por las investigadoras.

\begin{tabular}{|c|c|}
\hline \multicolumn{2}{|r|}{ Temas a explorar } \\
\hline Información socio demográfica & $\begin{array}{l}\text { - Edad, estado civil, tiempo de vivir en pareja, número de hijos, } \\
\text { escolaridad, ocupación, ingresos, acceso a vivienda y } \\
\text { servicios de salud, lugar de residencia y religión. }\end{array}$ \\
\hline Información clínica & $\begin{array}{ll}\text { - } & \text { Carga viral } \\
\text { - } & \text { Niveles CD4 } \\
\text { - } & \text { Tratamiento antirretroviral } \\
\text { - } & \text { Fase de la enfermedad } \\
\text { - } & \text { Atención a la salud mental } \\
\end{array}$ \\
\hline Diagnóstico & $\begin{array}{ll} & \text { Tiempo de diagnóstico } \\
\text { - ¿Por qué se hace la prueba? } \\
\text { - ¿Quién da el diagnóstico?¿Bajo q circunstancias? } \\
\text { - Impacto }\end{array}$ \\
\hline Representación social del VIH & $\begin{array}{ll}\text { - Nivel de información sobre el VIH y el SIDA } \\
\text { - } & \text { Material a partir del cual se construyen } \\
\text { - } & \text { Actitudes } \\
\end{array}$ \\
\hline Calidad de Vida & $\begin{array}{ll}\text { - } & \text { Soporte social } \\
\text { - } & \text { Estrategias de afrontamiento } \\
\text { - } & \text { Prácticas de auto cuidado } \\
\text { Presencia de estigma y discriminación }\end{array}$ \\
\hline
\end{tabular}




\section{(c) $(1)$}

Este texto está protegido por una licencia CreativeCommons $\underline{4.0}$

Usted es libre para Compartir — copiar y redistribuir el material en cualquier medio o formato - y Adaptar el documen- to -remezclar, transformar y crear a partir del material- para cualquier propósito, incluso comercialmente, siempre que cumpla la condición de:

Atribución: Usted debe reconocer el crédito de una obra de manera adecuada, proporcionar un enlace a la licencia, e in- dicar si se han realizado cambios. Puede hacerlo en cualquier forma razonable, pero no de forma tal que sugiera que tie- ne el apoyo del licenciante o lo recibe por el uso que hace.

$\underline{\text { Resumendelicencia - Textocompletodelalicencia }}$ 